\title{
SHORT-WAVE INFRARED ATMOSPHERIC SCHEIMPFLUG LIDAR
}

Mikkel Brydegaard $^{* 1,2,3}$, Jim Larsson ${ }^{2}$, Sandra Török ${ }^{2}$, Elin Malmqvist ${ }^{2}$, Guangyu Zhao ${ }^{4}$, Samuel Jansson $^{2}$, Mariam Andersson ${ }^{2}$, Sune Svanberg ${ }^{4,5}$, Susanne Åkesson ${ }^{3}$, Fredrik Laurell ${ }^{6}$, Joakim Bood ${ }^{2}$

${ }^{1}$ Norsk Elektro Optikk A/S, Norway, * mikkel.brydegaard@fysik.lth.se

${ }^{2}$ Combustion Physics Division, Department of Physics, Lund University, Sweden

${ }^{3}$ Centre for Animal Movement Research, Department of Biology, Lund University, Sweden

${ }^{4}$ Center for Optical and Electromagnetic Research, South China Normal University, Guangzhou, China

${ }^{5}$ Atomic Physics Division, Department of Physics, Lund University, Sweden

${ }^{6}$ Department of Applied Physics, Royal Institute of Technology, Stockholm, Sweden

\begin{abstract}
Atmospheric dual-band Scheimpflug lidar is demonstrated at 980 and $1550 \mathrm{~nm}$. Signals are compared during three weather conditions, and the spatio-temporal resolution of the atmospheric structure is considered. The potential for aerosol classification is evaluated, and future directions are discussed.
\end{abstract}

\section{SCHEIMPFLUG LIDAR}

In recent years we have developed the Scheimpflug lidar concept [1]. We have demonstrated the implementation for modulation spectroscopy on aerofauna [2], multiband aerosol monitoring [3, 4], polarimetric differential absorption lidar [5] and fluorescence and Raman lidar [6]. The method is based on high power CW laser diodes rather than pulsed solid-state lasers used in time-of-flight (ToF) lidars. Ranging is done by imaging the illuminated volume onto a tilted linear array. Utilizing the Scheimpflug condition and the Hinge rule, focus is maintained throughout the probe volume. Some advantages of Scheimpflug lidar are that resolution and range coverage can be scaled by scaling the optics. Also, whereas signal decays by $\mathrm{r}^{-2}$ and range resolution is constant in ToF lidar, this is the opposite for Scheimpflug lidar.

\section{SHORT-WAVE INFRARED LIDAR}

Until now, all implementations of Scheimpflug lidar have been based on Si CCD or CMOS arrays in the UV-NIR spectral region (405-808 $\mathrm{nm}$ ). In this report we demonstrate that the method is feasible in SWIR (900-1700 nm) by using an InGaAs array. Atmospheric ToF lidar in the SWIR region is generally challenging due to the low backscatter and the need for complex laser systems with Raman cells [7], OPO conversion [8] or fiber lasers with low peak power. In this report we show how atmospheric echoes can be retrieved in the SWIR range using the Scheimpflug lidar method.
Spectral bands can be chosen arbitrarily within the detection band, by replacing diode lasers for a cost comparable to that of a spectral filter. Lidar in the SWIR region has several benefits. The region has higher power density limits in relation to eye safety. The complex refractive index of liquid and frozen water has a detailed structure which can be indexed differentially through selecting appropriate laser wavelengths. Eumelanin is the most common pigment of the aerofauna, but because of its dull absorption spectrum $\left(\lambda^{-3.48}\right.$ from 280 to $1064 \mathrm{~nm}$ ) it is challenging to quantify without positioning a $\lambda_{\text {off }}$ band in the SWIR region. This method could potentially quantify melanization as function of wingbeat with $\mathrm{kHz}$ sampling [9]. Several atmospheric bulk and trace gases, such as $\mathrm{H}_{2} \mathrm{O}, \mathrm{CO}_{2}, \mathrm{CO}$ and $\mathrm{CH}_{4}$ have absorption bands in the SWIR region. Scheimpflug SWIR lidar can potentially map these species at high spatio-temporal resolution which can be realized with narrow-band seeded fiber amplifiers [10].

\section{SETUP AND TEST RANGE}

The instrument previously described $[3,11]$ was modified and equipped with a 2048 pixel $(12 \times 250 \mu \mathrm{m})$ InGaAs array. Two multimode $(100 \mu \mathrm{m}$ wide) diode lasers at $980 \mathrm{~nm}$ and $1550 \mathrm{~nm}$ were superimposed with a dichroic beam splitter. The total peak power was measured to $4.2 \mathrm{~W}$ and $2.5 \mathrm{~W}$, respectively (half of available output). The lasers are operated at $33 \%$ duty cycle synchronized with the line rate of the detector. Some $\sim 50 \%$ of the laser light was collected and expanded by a $ø 2 ", F / 3$, SWIR coated lens. The beam was transmitted from a laboratory window over the university campus and terminated on a roof at 980 $\mathrm{m}$ distance. The near limit was $35 \mathrm{~m}$ and at $70 \mathrm{~m}$ various particles were released. Backscattered light was collected by a $\varnothing 8 "$ Newtonian reflector with a InGaAs array tilted in the Scheimpflug 
condition. Normally, a dual bandpass filter is installed in front of the detector, but because of a mismatch the system was operated without filters. This limited the system to night-time operation or reduced exposure time (thus also reduced SNR) during daytime. In Fig. 1 data from three different atmospheric conditions is seen. As the scattering increases, so does the extinction. During clear conditions, flat atmospheric echoes are seen all way to the termination; this is characteristic for Scheimpflug lidars. The anomalies at $\mathrm{r}<50 \mathrm{~m}$ are caused by stray light and partial overlap of the beam and field-of-view.

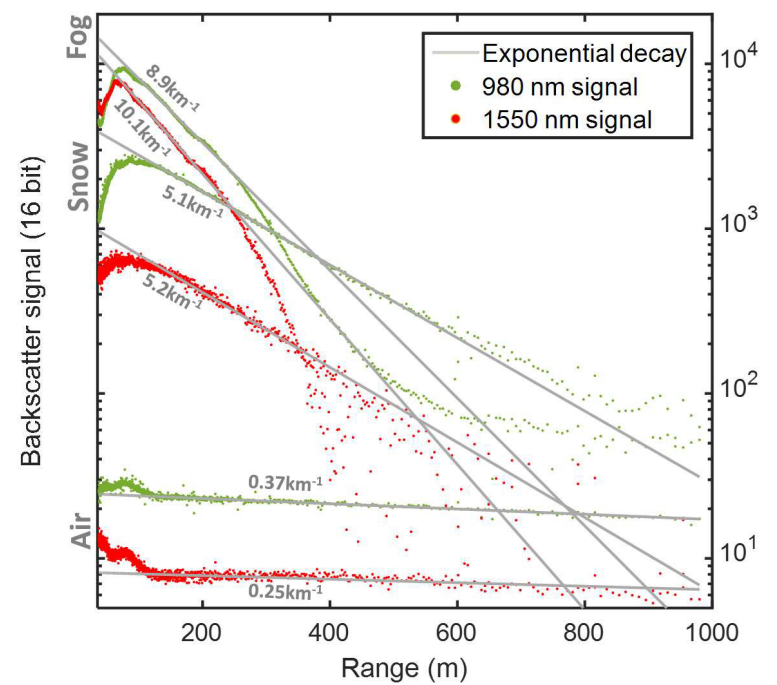

Fig. 1 Example of echoes during three different atmospheric conditions. The curves are normalized to the exposure time of $1 \mathrm{~ms}$ for comparison. For the highly scattering conditions, light is extinguished halfway to the termination.

\begin{tabular}{|c|c|c|c|c|c|c|c|c|}
\hline \begin{tabular}{|l} 
Date/ \\
time \\
\end{tabular} & Condition & $\Delta t$ & $\mathbf{T}$ & $\mathbf{V}$ & RH & $\begin{array}{l}\mu_{\text {ext }} \\
980 \mathrm{~nm}\end{array}$ & \begin{tabular}{|l|}
$\mu_{\text {ext }}$ \\
$1550 \mathrm{~nm}$
\end{tabular} & Experiments \\
\hline \begin{tabular}{|ll}
2016 \\
31 & Dec \\
$10 . .11$
\end{tabular} & \begin{tabular}{|l} 
Fog \\
Daylight
\end{tabular} & $\begin{array}{l}500 \\
\mu \mathrm{s}\end{array}$ & $+2{ }^{\circ} \mathrm{C}$ & $\begin{array}{l}\text { SE } \\
6 \mathrm{~m} / \mathrm{s}\end{array}$ & $\begin{array}{l}95 \\
\%\end{array}$ & $\begin{array}{l}8.9 \\
\mathrm{~km}^{-1}\end{array}$ & $\begin{array}{l}10.1 \\
\mathrm{~km}^{-1}\end{array}$ & $\begin{array}{l}\text { Wind } \\
\text { Homogeneity }\end{array}$ \\
\hline \begin{tabular}{|l}
2017 \\
5 Jan \\
$16 . .18$
\end{tabular} & $\begin{array}{l}\text { Clear } \\
\text { Darkness }\end{array}$ & $\begin{array}{l}2 \\
\mathrm{~ms}\end{array}$ & $-9{ }^{\circ} \mathrm{C}$ & $\begin{array}{l}\mathrm{NW} \\
3 \mathrm{~m} / \mathrm{s}\end{array}$ & $\begin{array}{l}48 \\
\%\end{array}$ & $\begin{array}{l}0.37 \\
\mathrm{~km}^{-1}\end{array}$ & $\begin{array}{l}0.25 \\
\mathrm{~km}^{-1}\end{array}$ & $\begin{array}{l}\text { Particle } \\
\text { release }\end{array}$ \\
\hline $\begin{array}{l}2017 \\
7 \text { Jan } \\
9 . .10\end{array}$ & \begin{tabular}{|l} 
Snow \\
Daylight
\end{tabular} & $\begin{array}{l}500 \\
\mu \mathrm{s}\end{array}$ & $-3^{\circ} \mathrm{C}$ & \begin{tabular}{|l}
$\mathrm{E}$ \\
$2 \mathrm{~m} / \mathrm{s}$
\end{tabular} & $\begin{array}{l}95 \\
\%\end{array}$ & $\begin{array}{l}5.1 \\
\mathrm{~km}^{-1}\end{array}$ & $\begin{array}{l}5.2 \\
\mathrm{~km}^{-1}\end{array}$ & \begin{tabular}{|l} 
Sparse \\
particles
\end{tabular} \\
\hline
\end{tabular}

\section{PARTICLE RELEASE}

Several types of aerosols and smoke were released at a test range of $70 \mathrm{~m}$. The plumes were identified when signal exceeded the static air scatter plus the noise [12]. The most distinct cases are displayed in Fig. 2 with further details in Table 2. The distribution displays large covariance. The general conception is that concentration (which is unknown in our experiment) alters the absolute scatter cross

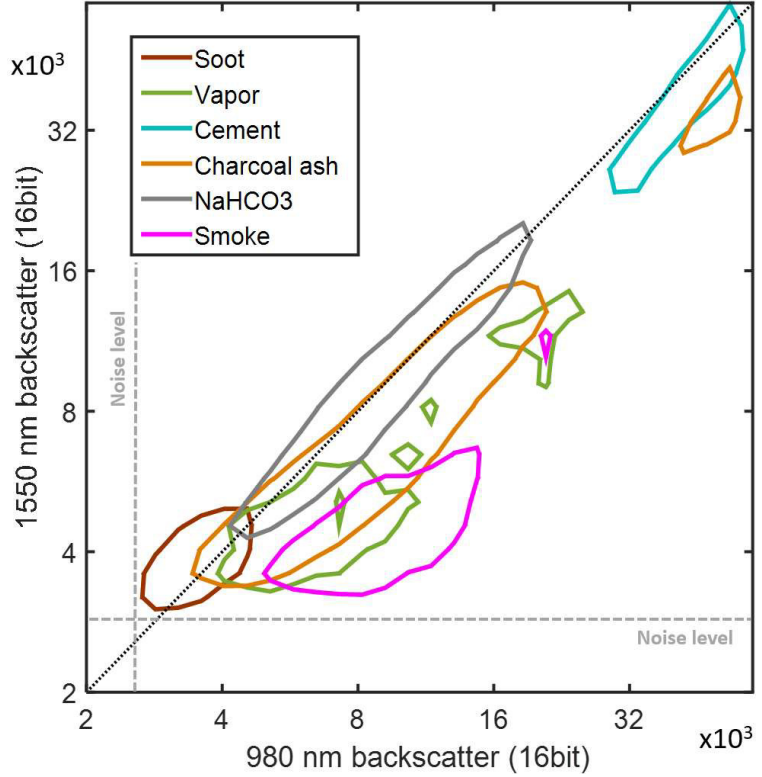

Fig. 2 The curves shows the midline contour of the $2 D$ distribution from hundreds of thousand time-range pixels from each plume.

section, whereas the type of aerosol alters the spectral slope. Large non-absorptive salts such as $\mathrm{NaHCO}_{3}$ align on the diagonal. New smoke with small particle sizes display strong scattering of the shorter band. Vapor, from the human breath, shows lower reflectance at $1550 \mathrm{~nm}$ where water absorbs. As can be expected the distributions heavily overlap and few aerosols occupy the upper triangle of the parameter space in Fig. 2. This could in principle be improved by placing strategic bands on the water absorption spectrum so that the shorter band coincides with higher water absorption. From the termination echo at $980 \mathrm{~m}$ range plume opacity was derived. However, backscatter from the plume saturates in most cases when significant extinction is detected.

Table 2. The various released particles plumes.
\begin{tabular}{|l|l|l|l|}
\hline Species & Release method & $\begin{array}{l}\text { Plume peak } \\
\text { opacity }\end{array}$ & $\begin{array}{l}\text { Spectral slope } \\
\mathbf{\sigma}_{1550} / \mathbf{\sigma 9 8 0}\end{array}$ \\
\hline Soot & Inverse vacuum & $39 \%$ & $110 \%$ \\
\hline Vapor & Exhalation & $10 \%$ & $57 \%$ \\
\hline Cement & Inverse vacuum & $56 \%$ & $84 \%$ \\
\hline Ash & Inverse vacuum & $87 \%$ & $70 \%$ \\
\hline NaHCO3 & Inverse vacuum & $27 \%$ & $100 \%$ \\
\hline Smoke & Tire burning & $25 \%$ & $48 \%$ \\
\hline
\end{tabular}

\section{RESOLVING ATMOSPHERIC STRUCTURES IN SPACE AND TIME}

One particular feature of Scheimpflug lidar is that it can reach spatial resolution down to a few $\mathrm{cm}$ (or less for other systems [13]) and temporal resolution of several $\mathrm{kHz}$ [12]. The idea of a homogeneous- or a granular atmosphere much depends on the spatio-temporal scale in question. 


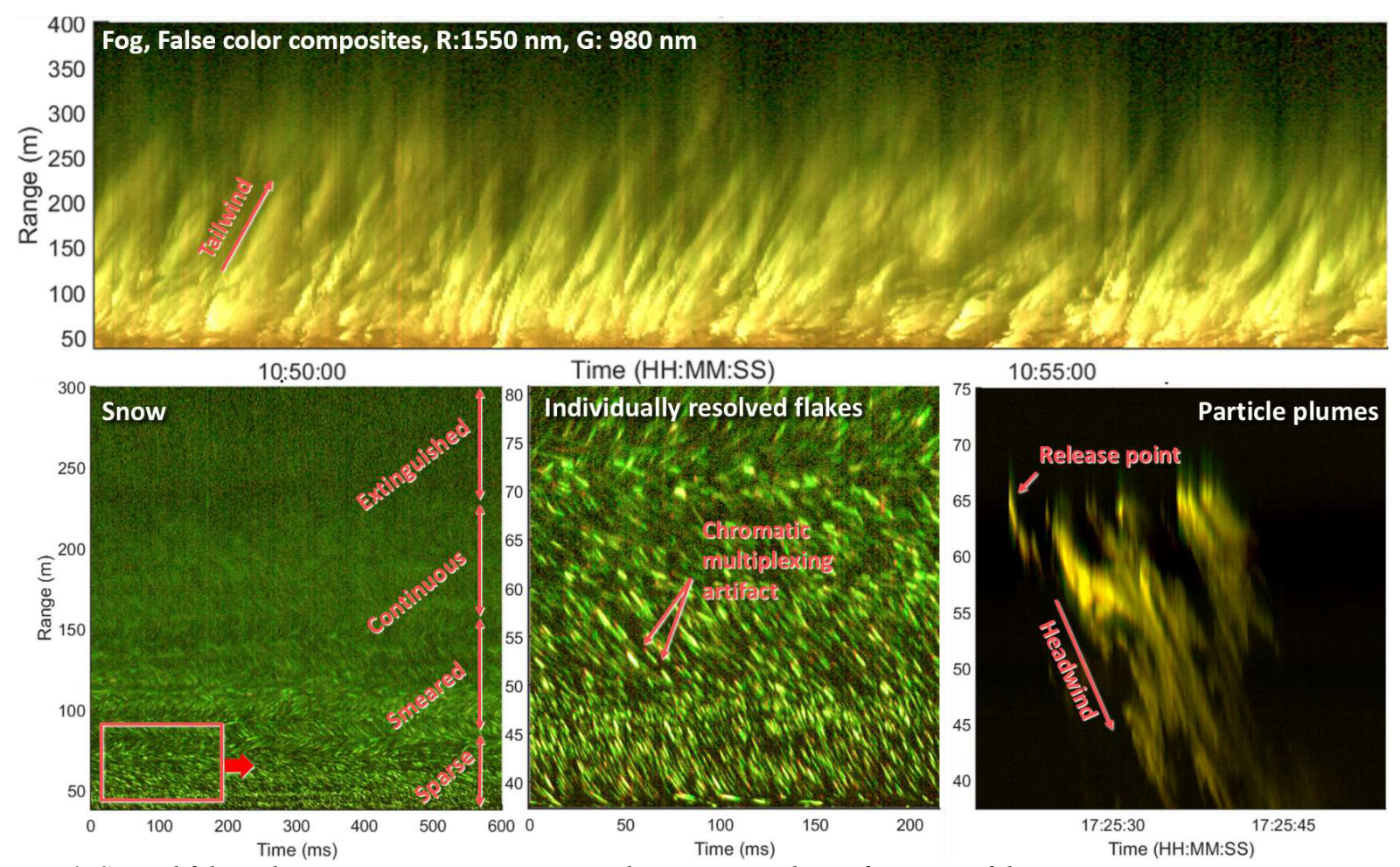

Fig. 3. Several false color composite time-range maps demonstrating the performance of the system.

Fig. 3 presents several false color composite time range maps for the days listed in Table 1 . In the top of Fig. 3, a 5 minute data stream of the first $400 \mathrm{~m}$ is observed where turbulent fluffy features blow through the probe volume at $6 \mathrm{~m} / \mathrm{s}$ tail wind. At a range of $400 \mathrm{~m}$ both wavelengths are essentially entirely extinguished in fog; compare to Fig.1 with the echo profiles of the same fog data. In contrast to snowy and clear conditions, fog displays distinct extinction for the two spectral bands. In the lower left case of snowy weather we observe a second data stream with a speckled pattern in the closest range. At farther ranges the speckles smear out, eventually becoming a continuously distributed back scatterer which is ultimately attenuated. The extinction during snowfall is roughly half of that during fog. When zooming into the closest range, a peculiar pattern of individual snowflakes is seen. Over longer time periods consistent structures, where the flakes blow in opposite directions at the same time but at different ranges can be observed. In Fig. 3 a simple background subtraction is employed. Because of the fast changing scenery during snow, both the background and the two bands are not measured instantaneously but in a time multiplexing sequence. It can be observed that flakes are red when entering the probe volume and green when they leave. This can be improved with more advanced interpolation techniques [3].
The last subfigure in Fig. 3, shows a plume from a teaspoon of $\mathrm{NaHCO}_{3}$ powder, which was released at $65 \mathrm{~m}$ range using an inverted vacuum cleaner. The time and range pixels for similar plumes were cropped out automatically and their scatter (in addition to the static scattering from clear air) was analyzed, see Fig. 2. The upper part of Fig. 4 shows how the statistical distribution and skewness varies with range (thus resolution) for different situations. Clean air produces Gaussians regardless of distance. Snow and fog display significant skewness when the spatial variance is resolved; However, the curvature is very different. The curves are presented for the $1550 \mathrm{~nm}$ scatter cross section, but similar findings can been obtained for $980 \mathrm{~nm}$. The temporal dynamics of the three situations are displayed in the lower row of Fig. 4. The clean air shows a static power spectrum on all ranges. Even when resolved, the fluffy fog only changes the scattering in the probe volume this fast and decays quickly with frequency. The sparse snowflakes, on the other hand, enter and leave the probe volume rapidly, and when spatially resolved, they show a broad frequency distribution. The overall common dampening towards the Nyquist frequencies is governed by the system bandwidth, which is a sinc function. 

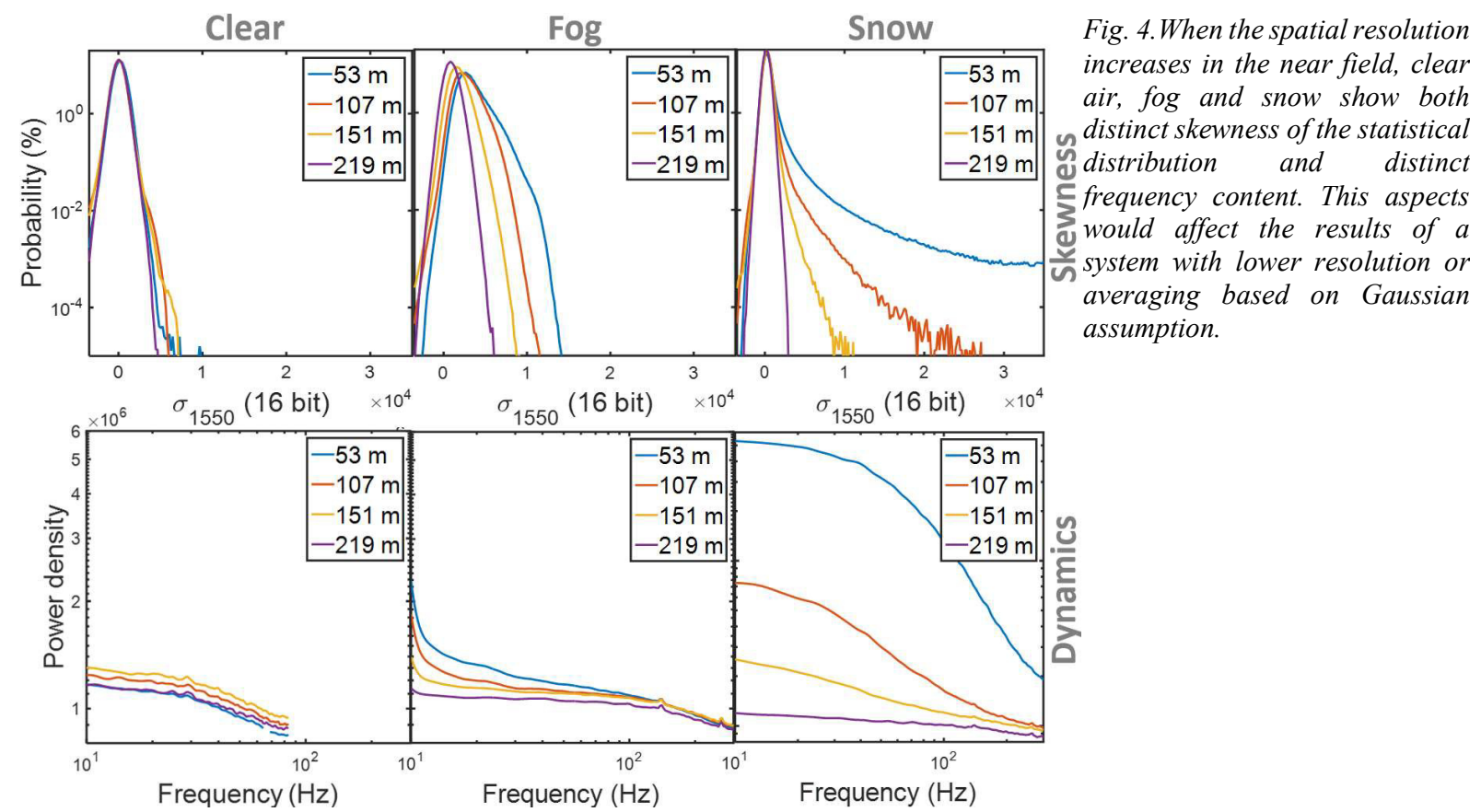

\section{CONCLUSION AND OUTLOOK}

We have shown that the atmospheric Scheimpflug lidar concept can be extended into the short-wave infrared range. Flat echoes from clean air $\left(\mu_{\text {att }}=0.32 \mathrm{~km}^{-1}\right)$ were retrieved with $\mathrm{SNR}=1$ at 32 ms exposure single shot, but the laser power could potentially be increased by a factor five. The system was tested in wintertime, and we are unsure if noise levels and line rates are sufficient for lidar entomology. However, some opportunities of high spatio-temporal resolution lidar were demonstrated. We hope to improve the system with dual-band pass filters, increased power, reduced stray light and to improve aerosol specificity by rearranging the bands. Further, we hope to pursue DIAL with seeded fiber lasers in the near future.

\section{ACKNOWLEDGEMENTS}

We appreciate the support from the Physiographical Society in Lund, from Norsk Elektro Optikk AS, from Lund University, from a Linnaeus grant to the Lund Laser Centre, and from the Swedish Research Council.

\section{REFERENCES}

[1] M. Brydegaard, A. Gebru, and S. Svanberg, "Super resolution laser radar with blinking atmospheric particles - application to interacting flying insects.," Prog. Electromagn. Res., vol. 147, pp. 141-151, 2014. M. Brydegaard, "Towards quantitative optical cross sections in entomological laser radar - Potential of temporal and spherical parameterizations for identifying atmospheric fauna," PLoS One, vol. 10, p. e0135231, 2015.
[3] G. Zhao, E. Malmqvist, S. Török, P.-E. Bengtsson, S. Svanberg, J. Bood, et al., "Dual-band continuous-wave lidar system employed for particle classification," To appear, 2017.

[4] L. Mei and M. Brydegaard, "Atmospheric aerosol monitoring by an elastic Scheimpflug lidar system," Optics Express, vol. 23, pp. A1613-A1628, 2015.

[5] L. Mei and M. Brydegaard, "Continuous-wave differential absorption lidar," Laser \& Photonics Reviews, vol. 9, pp. 629-636, 2015.

[6] G. Zhao, M. Ljungholm, E. Malmqvist, G. Bianco, L.-A. Hansson, S. Svanberg, et al., "Inelastic Hyperspectral Lidar for Profiling Aquatic Ecosystems," Laser \& Photonics Reviews, vol. 10, pp. 807-813, 2016.

[7] W. P. Hooper and G. M. Frick, "Lidar detected spike returns," J. Appl. Remote Sensing, vol. 4, p. 4(1) 043549, 2010.

[8] K. Numata, H. Riris, S. Li, S. Wu, S. R. Kawa, M. Krainak, et al., "Development of optical parametric amplifier for lidar measurements of trace gases on Earth and Mars," in SPIE Optical Engineering+ Applications, 2011, pp. 81590E-81590E-8.

[9] A. Gebru, M. Brydegaard, E. Rohwer, and P. Neethling, "Probing insect backscatter cross-section and melanization using $\mathrm{kHz}$ optical remote detection system," SPIE, Journal of Applied Remote Sensing, vol. 16611P, 2016.

[10] P. Zeil, V. Pasiskevicius, and F. Laurell, "Efficient spectral control and tuning of a high-power narrow-linewidth $\mathrm{Yb}$ doped fiber laser using a transversely chirped volume Bragg grating," Optics Express, vol. 21, pp. 4027-4035, 2013/02/25 2013.

[11] L. Mei and M. Brydegaard, "Development of a Scheimpflug lidar system for atmospheric aerosol monitoring," presented at the International Laser Radar conference 27, NYC, 2015.

[12] E. Malmqvist, S. Jansson, S. Torok, and M. Brydegaard, "Effective parameterization of laser radar observations of atmospheric fauna," Selected Topics in Quantum Electronics, IEEE Journal of, vol. PP, pp. 1-1, 2015. E. Malmqvist, M. Brydegaard, M. Aldén, and J. Bood, "CW-Laser Radar for Combustion Diagnostics," in Imaging and Applied Optics 2016, Heidelberg, 2016, p. LW2G.2. 